\title{
Spatio-temporal dependencies between hospital beds, physicians and health expenditure using visual variables and data classification in statistical table
}

\author{
Beata Medyńska-Gulij ${ }^{1}$, Pawel Cybulski² \\ Adam Mickiewicz University in Poznan \\ Faculty of Geographic and Geological Scienses \\ Department of Cartography and Geomatics \\ 27 Dzięgielowa St., 61-680 Poznan, Poland \\ e-mail: ${ }^{1}$ bmg@amu.edu.pl, ${ }^{2}$ pc29790@amu.edu.pl
}

Received: 12 May 2015 / Accepted: 10 October 2015

\begin{abstract}
This paper analyses the use of table visual variables of statistical data of hospital beds as an important tool for revealing spatio-temporal dependencies. It is argued that some of conclusions from the data about public health and public expenditure on health have a spatio-temporal reference. Different from previous studies, this article adopts combination of cartographic pragmatics and spatial visualization with previous conclusions made in public health literature. While the significant conclusions about health care and economic factors has been highlighted in research papers, this article is the first to apply visual analysis to statistical table together with maps which is called previsualisation.
\end{abstract}

Keywords: previsualisation, visual analysis, cartographic visualisation, public health, health expenditure

\section{Introduction}

The functioning of hospitals and access to health care systems has become the subject of numerous scientific publications in various fields. Interdisciplinary studies carried out over the past few years have contributed to the broadening of knowledge concerning the consequences of earlier actions undertaken in favour of health care. The number of publications and periodicals concerned with the issue of 'health' in the broadest meaning of the term testifies to the importance attached by contemporary science to issues relating to health care.

Earlier analyses of various authors provided a number of interesting conclusions, particularly as regards the costs connected with the functioning of hospitals. In this context, the issue of the costs of maintaining hospital beds or the requisite number of physicians is one that is frequently taken up. The earliest publications concerned with the analysis, status and utilisation of hospital beds were written at the beginning 
of the 20th century. Research into the literature allows us to distinguish two main trends - the reduction or improvement of management (Green, 2002; Green et al., 1995), and increasing expenditure on the health care system (Ham et al., 2003). In their conclusions, the authors note that the number of available hospital beds impacts access to the health care system and is to a considerable extent dependent on the financial resources allocated to the functioning of hospitals (Van Doorslaer and Van Vliet, 1989; Appleby, 2013).

It is interesting that only some publications take into consideration the spatial distribution of indices such as the number of hospital beds, the number of physicians, and expenditure on health care (Joseph and Philips, 1984; Khan, 1992; Kroneman and Siegers, 2004). The spatial analysis stresses the importance of geographical distribution, and may also point out the consequences and causes of such a state. It should be emphasised that contemporary health databases, made available by - for example - the WHO or the World Bank, contain information about changes in indices in individual years. The utilisation of these data makes it possible to broaden the spatial analysis by predictions of changes in the number of hospital beds, the number of physicians, and in expenditure on health care, which in conjunction with previous trends may be used to assess potential future changes.

In the present day, the number of spatial tools for analysing statistical data connected with the estimation, planning and drawing of conclusions concerning public health care is growing steadily. Amongst these works, we should mention Mosseveld (2003), Wei Luo (2004), Delamater, Messina and Grady (2013), Oliveira, Portela, Machado and Abelha (2014) and also Chakrabortty, Asadujjaman and Nuruzzman (2014).

The significance of cartographic visualisation in medicine relates to the presentation as a sui generis document concerning the spatial scope of diseases (Schweikart and Kisteman, 2013; Ocaña-Riola, 2010), or parts of reports elaborated for specialists, e.g. incidences of malignant neoplasms. The utilisation of on-line technologies for providing access to interactive atlases has also gained importance (Bhowmick et al., 2008).

The most friendly method of recording and understanding spatial dependencies by the public user and the professional user is the map, which is created during the process of cartographic visualisation using commonly available graphic and geoinformational technologies (Medyńska-Gulij, 2014). Typical techniques of quantitative thematic mapping that are read intuitively include the choropleth map and the proportional symbol map (Dent, 2008). Animated or semistatic maps are of considerable significance for the visualisation of data variable over time (Cybulski, 2014). Presently, statistical maps are created using statistical data entered in tables, which contain spatial references - usually to a country, city, or other administrative units.

The authors of the present article would like to propose a new method of spatial analysis - the previsualisation of the statistical table and a complementary cartographic visualisation, which would make it possible to draw new conclusions 
which takes into consideration spatio-temporal aspect. Finding patterns in statistical tables using visual analysis is a present-day issue (Klemm et al. 2014). In the present deliberations, the cartographic visualisation is considered as "the process of creating graphic presentations, usually in the form of a map, in order to become familiar with and clarify current spatial phenomena" (Medyńska-Gulij, 2011). The term "graphic previsualisation", in turn, is used herein to describe the process of applying graphic means for fields, columns and records of the statistical table - both for emphasis, and also to disclose statistical dependencies. Visual analysis focus on generating charts and even maps in order to better understand main characteristics in a data set (Kowarik et al., 2015). Computer programs offers various tools however, the authors aim was to make previsualization to be first step in visual analysis. Also it is important to keep systematic classification of data and colour palette in table as well as in a map.

The aim of this study is to put forward a new method of discovering dependencies for spatial phenomena connected with health using the method of previsualisation of tables of statistical data, and creating statistical maps on the basis thereof. An exemplary method of procedure will be presented utilising specific data concerning the number of hospital beds, the number of physicians, and expenditure on healthcare in the time context, in connection with other geographical data. Another objective is to utilise the previsualisation of the table for cartographic visualisation taking into consideration the degree of dependency, starting with the certain (i.e. obvious) relations, proceeding to those that may arise, and finishing with uncertain dependencies, solely conjectured by the researcher.

\section{Methodology}

The proposed methodical approach to the previsualisation of statistical tables with reference to geographical space comprises the following stages: selection of data, selection of previsualisation criteria, identification of dependencies in the table, cartographic visualisation of spatio-temporal dependencies, and the identification of dependencies on the map. All of these steps have been presented on the example of statistical data pertaining to health, chosen on the basis of conclusions drawn by the authors mentioned in the introduction to the present articles, and also geographical data.

\subsection{Selection of data}

The first stage was concerned with the selection of data concerning health care, which was dictated by the fact that insufficient emphasis was placed on the role of geographical space in analyses from the field of health care. For this reason, the authors decided to select indices of importance in terms of public health: the number 
of hospital beds per 100,000 inhabitants, the number of physicians per 100,000 inhabitants, and government expenditure on health care per capita in American dollars. In order to stress the geographical dimension, it was decided to choose European countries and the corresponding social features, i.e. the political system.

The level of unemployment, which impacts access to medical services, was selected as an additional index. In numerous health care systems maintained by European countries, the status of an unemployed person allows one to make use of state health insurance. According to some researchers, the unemployed are more exposed to the loss of mental health than those who are employed (Artazcoz et al., 2004). Three years were chosen for the purpose of drawing conclusions as to spatial variability: 2005, 2008, and 2011, since for these years the database is very complete. All of the data were taken from WHO database and the World Bank.

Authors did not searched for existence of statistical correlation however, they believe it is important to develop empirical study about the effectiveness of presented method.

\subsection{Selection of previsualisation criteria}

The first criterion in the process of previsualisation is the breakdown of data and the appropriate arrangement of columns in the table, according to the nature of the dependencies existing between data. Research into the literature shows that there are three types of dependencies between the selected data - dependencies that are certain, possible, and uncertain. Dependencies that are certain occur between the number of hospital beds per 100,000 inhabitants, the number of physicians per 100,000 inhabitants, and government expenditure on health care. They impact access to health care in a given country. The second type of dependency - possible - occurs between the number of unemployed and access to the health care system. The final type, i.e. uncertain dependencies, remains in the realm of conjecture, for these have not been disclosed by researchers to date. The authors of the present deliberations are considering whether the political system of a country, and therefore a specific policy approach, exerts a direct influence on access to health care. For this reason, the political system (PS) has been classified as an uncertain dependency. The columns in the table were ordered according to the hierarchy of these dependencies. Columns with the number of hospital beds (HBED), the number of physicians (PHYS), and health care expenditure (HE) were arranged according to individual years. A column with the rate of unemployment (UN) was added for each year group.

The second criterion is the time criterion, namely the ordering of columns in such a way as to ensure that they have headers informing about individual years. Thus, columns concerning the number of hospital beds, the number of physicians, expenditure on health care, and the rate of unemployment for the years 2005, 2008 and 2011 were grouped separately. The column with the political systems (PS) 
of individual countries was placed outside of the years, for the systems did not change over these periods. Rows in the table were arranged alphabetically using abbreviations for countries. Figure 1 presents the arrangement of columns and rows in the table according to two criteria - the nature of the dependency, and the time criterion.

The third criterion in the process of previsualisation is the application of graphic means of expression (Medyńska-Gulij, 2011), which in the proposed method means the allocation of colours, textures and symbols to individual table field, while at the same time maintaining the legibility of numerical values. Since certain dependencies are the most important, the authors allocated thereto the colours that in cartography are considered as the key visual variable (Dent, 2008). And thus, the colour blue was used to mark the number of hospital beds per 100,000 inhabitants. Red signifies the number of physicians per 100,000 inhabitants, while green marks expenditure on health care per capita. The second most important dependencies - possible dependencies - were marked with a grey line texture. Uncertain dependencies are denoted by symbols - republics by triangles, federations by rectangles, and monarchies by semicircles.

The fourth criterion in the classification of data. Only quantitative data were grouped into classes. In order for the previsualisation to be intelligible, and also to ensure that the number of classes does not hinder the search for dependencies, the authors decided to use between 4 and 5 classes, in accordance with Jenks' division (Jenks, 1967). The number of hospital beds and expenditure on health care were grouped in 5 classes, while the number of physicians in 4 classes. Next, unemployment rate was divided into 3 classes, determined arbitrarily. The division into classes made it necessary to break down colours into classes of brightness, where the smallest value would correspond to the greatest brightness of a given colour. Data classification has been chosen arbitrary based on knowledge of authors. However, different method of classification are also possible i.e. natural breaks, equidistant groups. There should not be more than 7 classes to not overload user with symbols and colours (MedyńskaGulij, 2011).

The fifth criterion is that of extremity, i.e. the indication of maximums and minimums for the entirety of data, and also for individual years. In the process of previsualisation of tables, maximums and minimums constitute certain points of reference, and for this reason it has been decided to emphasise them. A thick line was used to mark the maximum for each quantitative phenomenon in each individual year, and also one maximum for each phenomenon over three years. An identical approach was applied for minimum values, and graphic emphasis was used by strengthening the lines of table fields with a thick dotted line. Figure 2 presents the previsualisation with the maintenance of five criteria. 


\begin{tabular}{|c|c|c|c|c|c|c|c|c|c|c|c|c|c|c|}
\hline \multirow[b]{2}{*}{$L P$} & \multirow[b]{2}{*}{ STATE } & \multicolumn{4}{|c|}{2005} & \multicolumn{4}{|c|}{2008} & \multicolumn{4}{|c|}{2011} & \multirow[b]{2}{*}{ PS } \\
\hline & & HBED & PHYS & $H E$ & UN & HBED & PHYS & $H E$ & UN & HBED & PHYS & $H E$ & UN & \\
\hline 1. & ALB & 296.6 & & 160.2 & 14.1 & & & 251.4 & 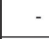 & 260.5 & 111.3 & 242.9 & 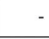 & $\mathrm{R}$ \\
\hline 2. & AUT & 768.9 & 431.8 & 3863.1 & 5.2 & 769.3 & 460.4 & 5211.4 & 3.8 & 767.9 & 484.4 & 5643.0 & 4.2 & $\mathrm{~F}$ \\
\hline 3. & BEL & 742.5 & 287.1 & 3606.4 & 8.5 & 657.4 & 292.1 & 4715.1 & 7.0 & 635.1 & 291.4 & 4913.7 & 7.2 & M \\
\hline 4. & $\mathrm{BIH}$ & 320.8 & 151.6 & 245.8 & - & 333.4 & 162.0 & 424.5 & 23.4 & & & 471.2 & 27.6 & $\mathrm{~F}$ \\
\hline 5. & BLR & 1112.9 & 328.9 & 215.2 & 1.5 & 1112.2 & 352.2 & 378.2 & 0.8 & 1125.1 & 379.1 & 311.2 & 0.6 & $R$ \\
\hline 6. & BUL & 641.2 & 364.0 & 273.5 & 10.1 & 649.4 & 360.1 & 474.1 & 5.6 & 644.9 & 386.2 & 521.5 & 11.3 & $R$ \\
\hline 7. & CRO & 545.3 & 249.9 & 704.9 & 12.6 & 547.6 & 266.1 & 1224.0 & 8.3 & 578.8 & 283.6 & 991.8 & 13.4 & $R$ \\
\hline 8. & CYP & 383.3 & 266.0 & 1434.1 & 5.3 & 376.3 & 280.4 & 2182.1 & 3.7 & 349.0 & 298.2 & 2123.2 & 7.9 & $\mathrm{~F}$ \\
\hline 9. & CZE & 755.4 & 355.5 & 882.4 & 7.9 & 718.4 & 354.0 & 1480.7 & 4.4 & 683.5 & 363.6 & 1545.4 & 6.7 & $\mathrm{R}$ \\
\hline 10. & DEN & 385.9 & 331.1 & 4652.2 & 4.8 & 357.4 & 343.0 & 6395.0 & 1.9 & & - & 6521.4 & 7.6 & $M$ \\
\hline 11. & ESP & 336.1 & 376.7 & 2177.7 & 9.2 & 322.2 & 349.8 & 3145.8 & 11.3 & 309.2 & 398.9 & 2977.6 & 21.6 & $M$ \\
\hline 12. & EST & 541.7 & 316.5 & 512.5 & 7.9 & 561.7 & 333.3 & 1059.8 & 5.5 & 530.9 & 326.3 & 927.8 & 12.5 & $\mathrm{R}$ \\
\hline 13. & FIN & 705.3 & 263.4 & 3151.5 & 8.4 & 656.8 & 272.1 & 4262.3 & 6.4 & 552.1 & & 4411.3 & 7.8 & $R$ \\
\hline 14. & FRA & 746.2 & - & 3749.9 & 8.9 & 711.0 & - & 4876.9 & 7.4 & 656.4 & 316.1 & 4968.2 & 9.2 & $R$ \\
\hline 15. & GBR & 373.3 & 239.3 & 3161.2 & 4.8 & 335.5 & 257.6 & 3875.2 & 5.6 & 291.6 & 277.7 & 3658.9 & 8.0 & $M$ \\
\hline 16. & GER & 846.8 & 341.1 & 3624.2 & 11.2 & 821.3 & 355.7 & 4717.7 & 7.5 & 822.4 & 382.3 & 4995.9 & 5.9 & $\mathrm{~F}$ \\
\hline 17. & GRE & 472.9 & 500.3 & 2092.9 & 9.8 & 477.5 & 603.3 & 3084.8 & 7.6 & & 614.4 & 2304.0 & 17.7 & $\mathrm{R}$ \\
\hline 18. & HUN & 785.4 & 278.1 & 922.7 & - & 710.5 & 309.0 & 1145.7 & 7.8 & 718.7 & 295.8 & 1095.6 & 10.9 & $R$ \\
\hline 19. & IRL & 549.8 & - & 3733.8 & 4.4 & 492.7 & - & 5393.2 & 6.4 & 294.8 & 267.0 & 4305.7 & 14.4 & $\mathrm{R}$ \\
\hline 20. & ISL & - & 361.7 & 5329.5 & 2.6 & 392.4 & 362.6 & 4959.4 & 3.0 & 331.9 & 351.1 & 4050.6 & 7.1 & $\mathrm{R}$ \\
\hline 21. & ITA & 404.3 & & 2671.6 & 7 & 372.7 & & 3441.0 & 6.7 & 350.2 & 418.8 & 3339.1 & 8.4 & $\mathrm{R}$ \\
\hline 22. & LAT & 768.4 & 288.1 & 441.6 & 9.0 & 746.1 & 310.6 & 978.7 & 7.7 & 588.0 & 313.4 & 826.3 & 16.2 & $\mathrm{R}$ \\
\hline 23. & LTU & 708.8 & 362.0 & 446.0 & 8.3 & 683.7 & 369.6 & 934.4 & 5.8 & 744.6 & 409.7 & 887.3 & 15.4 & $\mathrm{R}$ \\
\hline 24. & LUX & 578.5 & 255.0 & 6484.8 & 4.6 & 556.8 & 271.5 & 8305.1 & 5.0 & - & 275.7 & 7751.3 & 4.9 & $M$ \\
\hline 25. & MDA & 638.7 & 279.1 & 76.0 & 2.0 & 610.6 & 277.6 & 193.4 & 1.6 & 618.8 & 282.6 & 223.7 & 3.6 & $R$ \\
\hline 26. & MKD & 469.8 & 215.6 & 231.4 & 37.3 & 454.6 & 262.0 & 325.1 & 33.8 & 449.6 & 273.7 & 343.6 & 31.4 & $\mathrm{R}$ \\
\hline 27. & MLT & 745.2 & - & 1393.9 & 5.1 & 734.2 & - & 1596.2 & 6.0 & 446.7 & 324.3 & 1900.1 & 6.5 & $R$ \\
\hline 28. & MNE & 418.4 & 192.7 & 319.1 & 30.3 & 385.2 & 207.5 & 465.5 & 16.8 & 397.4 & 201.6 & 521.9 & 19.7 & $\mathrm{R}$ \\
\hline 29. & NED & 445.5 & 270.8 & 4261.0 & 5.3 & 469.9 & 287.0 & 5834.0 & 3.1 & & & 5997.3 & 4.4 & M \\
\hline 30. & NOR & 404.4 & 362.0 & 6293.3 & 4.4 & 351.7 & 400.3 & 8626.2 & 2.5 & 331.5 & 371.7 & 9908.2 & 3.3 & M \\
\hline 31. & POL & 652.1 & 213.8 & 494.2 & 17.6 & 662.1 & 216.1 & 955.8 & 9.5 & 654.8 & 218.6 & 915.3 & 12.5 & $R$ \\
\hline 32. & POR & 355.8 & 336.5 & 1886.4 & 7.6 & 339.1 & 361.3 & 2424.6 & 7.6 & 337.8 & 398.3 & 2302.0 & 12.7 & $\mathrm{R}$ \\
\hline 33. & ROU & 677.6 & 217.2 & 251.1 & - & 657.2 & 221.4 & 516.4 & 5.8 & 610.7 & 238.5 & 479.6 & 7.4 & $\mathrm{R}$ \\
\hline 34 & RUS & 974.2 & 424.6 & 276.7 & 7.2 & - & 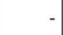 & 594.3 & 0.5 & & & 802.5 & 6.6 & $\mathrm{~F}$ \\
\hline 35. & SLO & 483.0 & 234.5 & 1494.0 & 6.5 & 470.0 & 238.0 & 2264.9 & 4.4 & 462.5 & 249.5 & 2170.6 & 8.2 & $\mathrm{R}$ \\
\hline 36. & SRB & - & 279.4 & 307.0 & 21.8 & - & 298.4 & 673.4 & 14.4 & - & 308.7 & 622.4 & 23.6 & $\mathrm{R}$ \\
\hline 37. & SUI & 553.9 & & 5636.5 & 3.8 & 521.1 & 381.7 & 7103.9 & - & 500.7 & 394.1 & 9247.8 & 4.1 & $\mathrm{~F}$ \\
\hline 00.1 & SVK & 676.7 & & 626.6 & 16.3 & 655.6 & & 1399.9 & 9.6 & 605.5 & & 1414.8 & 13.5 & $R$ \\
\hline 39. & SWE & 293.2 & & 3726.4 & 6.0 & 280.5 & & 4885.6 & 6.2 & 270.5 & & 5418.8 & 7.6 & $M$ \\
\hline 40. & UKR & 868.3 & 301.6 & 117.2 & 7.2 & 874.5 & 312.3 & 257.0 & 6.4 & 904.8 & 349.1 & 261.8 & & $R$ \\
\hline
\end{tabular}

Fig. 1 - Order of the table using temporal and depending criteria [HBED - hospital beds per 100000 people, PHYS - physicians per 100000 people, HE - health expenditure per capita in U.S. dollars, $\mathrm{UN}$ - unemployment rate, PS - political system ( $\mathrm{R}$ - republic, F - federation, $\mathrm{M}$ - monarchy). 


\begin{tabular}{|c|c|c|c|c|c|c|c|c|c|c|c|c|c|c|c|}
\hline & & & 2005 & & & & 2008 & & & & & 2011 & & & Map key: \\
\hline LP & STATE & HBED & PHYS & HE & UN & HBED & PHYS & HE & UN & HBED & PHYS & HE & UN & PS & \\
\hline 1. & ALB & 296.6 & & 160.2 & 14.1 & - & & 251.4 & & 260.5 & 111.3 & 242.9 & & $B$ & e \\
\hline 2. & AUT & 768.9 & 431.8 & 3863.1 & 5.2 & 769.3 & 460.4 & 5211.4 & 3.8 & 767.9 & 84.4 & 5643.0 & 4.2 & $F$ & $904.9-1125.1$ \\
\hline 3. & BEL & 742.5 & 287.1 & 3606.4 & 8.5 & 657.4 & 292.1 & 4715.1 & 7.0 & 635.1 & 291.4 & 4913.7 & 7.2 & M & $683.8-904.8$ \\
\hline 4. & $\mathrm{BIH}$ & 320.8 & 151.6 & 245.8 & - & 333.4 & 162.0 & 424.5 & 23.4 & - & & 471.2 & 27.6 & $F$ & $561.8-683.7$ \\
\hline 5. & BLR & 1112.9 & 328.9 & 215.2 & 15 & 1112.2 & 352.2 & 378.2 & 0.8 & 1125.1 & 379.1 & 311.2 & 0,6 & $B$ & $418.5-561.7$ \\
\hline 6. & BUL & 641.2 & 364.0 & 273.5 & 10.1 & 649.4 & 360.1 & 474.1 & 5.6 & 644.9 & 386.2 & 521.5 & 11,3 & $B$ & $260.5-418.4$ \\
\hline 7. & CRO & 545.3 & 249.9 & 704.9 & 12,6 & 547.6 & 266.1 & 1224.0 & 8.3 & 578.8 & 283.6 & 991.8 & 13,4 & B & \\
\hline 8. & CYP & 383.3 & 266.0 & 1434.1 & 5.3 & 376.3 & 280.4 & 2182.1 & 3.7 & 349.0 & 298.2 & 2123.2 & 7.9 & $F$ & \\
\hline 9. & CZE & 755.4 & 355.5 & 882.4 & 7.9 & 718.4 & 354.0 & 1480.7 & 4.4 & 683.5 & 363.6 & 1545.4 & 6.7 & $B$ & people \\
\hline 10. & DEN & 385.9 & 331.1 & 4652.2 & 4.8 & 357.4 & 343.0 & 6395.0 & 1.9 & & & 6521.4 & 7,6 & M & $431.9-614.4$ \\
\hline 11. & ESP & 336.1 & 376.7 & 2177.7 & 9.2 & 322.2 & 349.8 & 3145.8 & 11.3 & 309.2 & 398.9 & 2977.6 & 21.6 & M & $324.4-431.8$ \\
\hline 12. & EST & 541.7 & 316.5 & 512.5 & 7.9 & 561.7 & 333.3 & 1059.8 & 5.5 & 530.9 & 326.3 & 927.8 & 12.5 & $B$ & $293.4-324.3$ \\
\hline 13. & FIN & 705.3 & 263.4 & 3151.5 & 8.4 & 656.8 & 272.1 & 4262.3 & 6.4 & 552.1 & & 4411.3 & 7.8 & $B$ & - \\
\hline 14. & FRA & 746.2 & - & 3749.9 & 8.9 & 711.0 & - & 4876.9 & 7.4 & 656.4 & 316.1 & 4968.2 & 9.2 & $R$ & \\
\hline 15. & GBR & 373.3 & 239.3 & 3161.2 & 4.8 & 335.5 & 257.6 & 3875.2 & 5.6 & 291.6 & 277.7 & 3658.9 & 8.0 & M & \\
\hline 16. & GER & 846.8 & 341.1 & 3624.2 & 11.2 & 821.3 & 355.7 & 4717.7 & 7.5 & 822.4 & 382.3 & 4995.9 & 5.9 & $\mathrm{~F}$ & expe \\
\hline 17. & GRE & 472.9 & 500.3 & 2092.9 & 9.8 & 477.5 & 13.3 & 3084.8 & 7.6 & & 614.4 & 2304.0 & 17.7 & B & \\
\hline 18. & HUN & 785.4 & 278.1 & 922.7 & - & 710.5 & 309.0 & 1145.7 & 78 & 718.7 & 295.8 & 1095.6 & 10.9 & $R$ & 6521.5 - 9908.2 \\
\hline 19. & IRL & 549.8 & & 3733.8 & 4.4 & 492.7 & -1 & 5393.2 & 6.4 & 294.8 & 267.0 & 4305.7 & 14.4 & B & $4411.4-6521.4$ \\
\hline 20. & ISL & - & 361.7 & 5329.5 & 2.6 & 392.4 & 362.6 & 4959.4 & 3.0 & 331.9 & 351.1 & 4050.6 & 7.1 & B & $2671.7-4411.3$ \\
\hline 21. & ITA & 404.3 & & 2671.6 & 77 & 372.7 & & 3441.0 & 6.7 & 350.2 & 418.8 & 3339.1 & 8.4 & B & $1145.8-2671.6$ \\
\hline 22. & LAT & 768.4 & 288.1 & 441.6 & 9.0 & 746.1 & 310.6 & 978.7 & 7.7 & 588.0 & 313.4 & 826.3 & 16.2 & B & $76.0-1145.7$ \\
\hline 23. & LTU & 708.8 & 362.0 & 446.0 & 8,3 & 683.7 & 369.6 & 934.4 & 5.8 & 744.6 & 409.7 & 887.3 & 15.4 & B & \\
\hline 24. & LUX & 578.5 & 255.0 & 6484.8 & 4.6 & 556.8 & 271.5 & 8305.1 & 5.0 & & 275.7 & 7751.3 & 4.9 & $M$ & 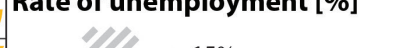 \\
\hline 25. & MDA & 638.7 & 279.1 & 76.0 & 2.0 & 610.6 & 277.6 & 193.4 & 1.6 & 618.8 & 282.6 & 223.7 & 3.6 & B & $>15 \%$ \\
\hline 26. & MKD & 469.8 & 215.6 & 231.4 & 37.3 & 454.6 & 262.0 & 325.1 & 33.8 & 449.6 & 273.7 & 343.6 & 31.4 & B & $5,1-15 \%$ \\
\hline 27. & MLT & 745.2 & - & 1393.9 & 5.1 & 734.2 & & 1596.2 & 6.0 & 446.7 & 324.3 & 1900.1 & 6.5 & $B$ & $0-5 \%$ \\
\hline 28. & MNE & 418.4 & 192.7 & 319.1 & 30.3 & 385.2 & 207.5 & 465.5 & 16.8 & 397.4 & 201.6 & 521.9 & 19.7 & B & \\
\hline 29. & NED & 445.5 & 270.8 & 4261.0 & 5,3 & 469.9 & 287.0 & 5834.0 & 3.1 & & & 5997.3 & 4,4 & $M$ & Political System \\
\hline 30. & NOR & 404.4 & 362.0 & 6293.3 & 4.4 & 351.7 & 400.3 & 8626.2 & 2.5 & 331.5 & 371.7 & 9908.2 & 3,3 & $M$ & Republic \\
\hline 31. & POL & 652.1 & 213.8 & 494.2 & 17.6 & 662.1 & 216.1 & 955.8 & 9.5 & 654.8 & 218.6 & 915.3 & 12.5 & $B$ & Monarchy \\
\hline 32. & POR & 355.8 & 336.5 & 1886.4 & 7.6 & 339.1 & 361.3 & 2424.6 & 7.6 & 337.8 & 398.3 & 2302.0 & 12.7 & $B$ & Federation \\
\hline 33. & ROU & 677.6 & \begin{tabular}{|l|}
217.2 \\
\end{tabular} & 251.1 & - & 657.2 & 221.4 & 516.4 & 5.8 & 610.7 & 238.5 & 479.6 & 7.4 & $B$ & \\
\hline 34. & RUS & 974.2 & 424.6 & 276.7 & 7.2 & - & & 594.3 & 6.3 & - & & 802.5 & 6.6 & $\mathrm{~F}$ & \\
\hline 35. & SLO & 483.0 & 234.5 & 1494.0 & 6.5 & 470.0 & 238.0 & 2264.9 & 4.4 & 462.5 & 249.5 & 2170.6 & 8,2 & $B$ & \\
\hline 36. & SRB & & 279.4 & 307.0 & 21.8 & & 298.4 & 673.4 & 14.4 & & \begin{tabular}{|l|}
308.7 \\
\end{tabular} & 622.4 & 23.6 & B & \\
\hline 37. & SUI & 553.9 & 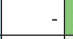 & 5636.5 & 3.8 & 521.1 & 381.7 & 7103.9 & - & 500.7 & 394.1 & 9247.8 & 4,1 & $\mathrm{~F}$ & \\
\hline 38. & SVK & 676.7 & - & 626.6 & 16.3 & 655.6 & & 1399.9 & 9.6 & 605.5 & & 1414.8 & 13,5 & B & \\
\hline 39. & SWE & 293.2 & & 3726.4 & 6.0 & 280.5 & & 4885.6 & 6.2 & 270.5 & & 5418.8 & 7,6 & M & \\
\hline 40. & UKR & 868.3 & 301.6 & 117.2 & 7,2 & 874.5 & 312.3 & 257.0 & 6.4 & 904.8 & 349.1 & 261.8 & & $B$ & \\
\hline
\end{tabular}

Fig. 2 - Previsualisation using five criteria 


\subsection{Identification of dependencies in the table}

The identification of dependencies in the table starts off with a search for certain dependencies proceeding to ones that are possible and uncertain. As regards the number of beds, there is a clear trend aiming at decreasing the number of beds during the period 2005-2011. The greatest number of beds was maintained by Belarus. The smallest number of hospital beds was noted in Sweden, and only in 2011 did Albania take first place in this category. As regards the number of physicians, the situation is the reverse during the same period. The number of physicians increased in the majority of countries. The largest number of physicians per 100,000 inhabitants in each year was observed in Greece. The smallest number per 100,000 inhabitants was observed in Bosnia and Herzegovina, and in Albania in 2011. Similarly, expenditure on health care rose over these few years. However, in a few cases there appeared an interesting dependency between expenditure on health care and the rate of unemployment. In certain countries that increased their expenditure on health care in the period 20052008, the rate of unemployment grew considerably in 2011, namely in Austria, Bulgaria, Croatia, Cyprus, Denmark, Spain, Estonia, Finland, Greece, Hungary, Italy, Latvia, Lithuania, Poland, Portugal, Romania, Slovenia, Serbia, Slovakia and Sweden. In 2005, the greatest expenditure on health care was incurred by Luxemburg, while in the period 2008-2011 - by Norway. Moldavia spent the smallest amount on health care every year.

The unemployment rate fell between 2005 and 2008, while in 2011 it increased in comparison with the preceding period. Greater levels of unemployment in Europe were observed for republics. The lowest level of unemployment in all of these years was noted in Belarus, and the highest in Macedonia. During the period 2005-2008, monarchies had a relatively smaller number of hospital beds than republics and federations.

\subsection{Cartographic visualisation of spatio-temporal dependencies}

The cartographic visualisation of dependencies follows from the final, sixth, criterion - the spatial criterion. This was presented separately, for it entails the spatial ordering of data, with the map being the best method. However, the visualisation of the dependencies set forward in the table is performed according to cartographic rules. In addition, the previsualisation of the table and the cartographic visualisation of dependencies must be complementary, and for this reason the markings used in the table should be visible on the map. The elaborated data determine the available possibilities for creating a statistical map.

The mapping methods are clearly specified for the two types of data (quantitative and qualitative) present in the table (Ratajski, 1989; Medyńska-Gulij, 2011). For the first type - certain dependencies, a map was elaborated and the following mapping methods adopted. The choropleth map was used for the number of hospital beds, 
this being concordant with the selected colour and the previously adopted Jenks' classification (Jenks, 1967). This is the simplest method of showing quantitative data, and also the basis for further modifications. The number of physicians has been presented on the maps by pictographic proportional height symbols presenting a man (Kraak and Ormeling, 2010). The final phenomenon in certain dependencies, i.e. expenditure on health care, has been presented by means of a predominance, where the height of the statistical surface corresponds to the value of expenditure incurred by governments on health care (Slocum et al., 2009). The map showing certain dependencies has been presented in Figure 4. We should note that not everything may be shown as precisely on the map as in Figure 2, however the authors have attempted to maintain consistency in both the selection of colours and mapping methods.

Possible dependencies are illustrated by a texture added to maps containing certain dependencies. In Figure 2, the colour of the texture was grey, however due to the quantity of information contained in the map, black was used in order to make the dependencies visible. Figure 4 presents the map of possible dependencies. It should be observed that together with the increasing quantity of information on the map, it becomes more difficult to read; among others, this is dictated by the hierarchy of dependencies. Certain dependencies were simple to read, but as successive information was added, this became steadily more difficult and, finally, uncertain, nevertheless noteworthy for the researcher.

Uncertain dependencies are connected with the political systems of countries. Political system is just an example of characteristic which is slightly connected with a health system. Distinction between republic, federation and monarchy was dictated by different redistribution of GDP. Federations have more autonomy on this and could have more influence on financing health care system. The same was with monarchy which have bodies like Privy Council that can help financing health care in their countries (Ferguson, 2007). As regards the previously utilised mapping methods, the authors decided to use the method of scopes in order to mark the occurrence of specific political systems in Europe. Just as in the table, use was made of triangles, semicircles and rectangles to denote political systems. In order to ensure better emphasis, scopes were marked in orange. In this way we arrived at Figure 5, which is the most difficult to interpret - just as the uncertainty of the relations that it presents. 


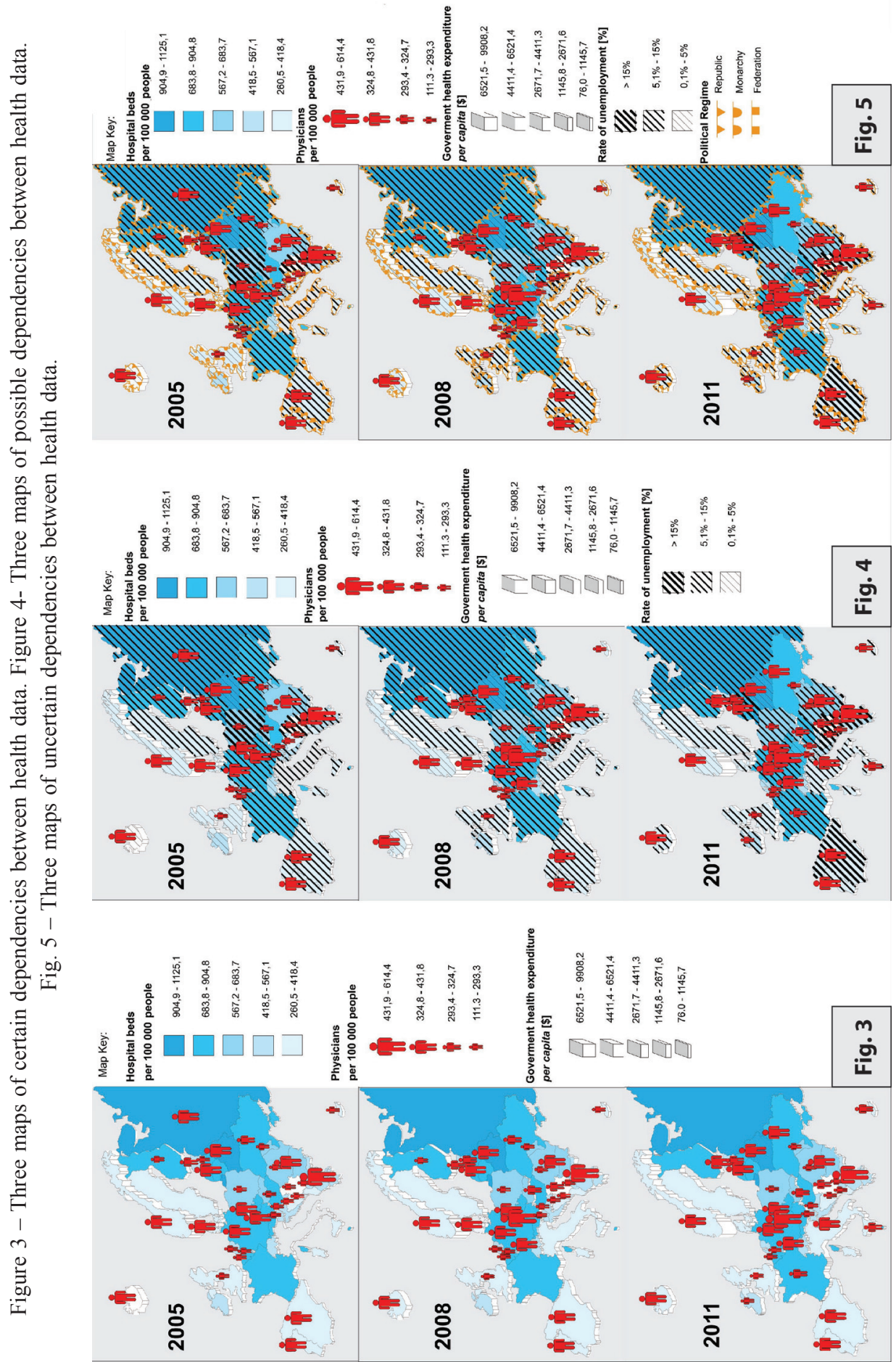




\subsection{Identification of dependencies on the map}

The identification of dependencies on the map begins with certain dependencies, proceeding to possible and, finally, to uncertain ones. Connection of table previsualization with map visualization can support detection of these dependencies. Amongst the certain dependencies we may observe that the number of hospital beds per 100,000 inhabitants is lower in peripheral areas, and higher in the continental part; this tendency did not change throughout the analysed period. The number of physicians per 100,000 inhabitants is regional in nature. There are five regions with greater numbers of physicians - the eastern, central, western, southern and northern. These regions are separated from each other by areas with a lower number of physicians. The nature of this arrangement became steadily more pronounced over the three years. In turn, expenditure on health care divides Europe into two parts - the eastern and the western, with the latter spending considerably more funds per capita. The increase in health expenditure appears to shift towards the east.

Possible dependencies, i.e. connections between the rate of unemployment and the health care system, develop similarly to the number of hospital beds, however with the difference that the unemployment rate shifts over time from the continental part to peripheral areas.

Uncertain dependencies are presented by political systems. Figure 5 clearly shows that the area of the republic in the central part is characterised by a lower number of physicians than the surrounding area. Furthermore, unemployment has clearly increased in the south and north-east of the republic. Expenditure on health care has also increased in the western republic. In the monarchy, unemployment has risen with the exception of the Benelux countries. The federation, in turn, has experienced an increase in the number of physicians, and also a fall in unemployment. It is also visible that monarchies have a relatively smaller number of beds per 100,000 inhabitants.

\section{Results}

The previsualisation of the table and statistical maps, which are the result of the process of cartographic visualisation, do not form the basis for drawing the same conclusions and do not present the same dependencies, and for this reasons the authors suggest that their application should be complementary. It is because of that statistical table are not spatially organized. Although the previsualisation of the table and the map differ as regards interpretation, the conclusions drawn are supplementary, and may offer new interpretative possibilities for specialists occupied with health care. To draw supplementary conclusions the same data classification and visual representation is needed. Small number of classes can generalize dependencies and on the other hand too much classes can cause the map and table unreadable. However, like the example, the same methods of visualization could not been adopted. This can lead to misinterpretation. On the basis of the map and table we may observe, that countries in 
which their occurred a dependency between an increase in expenditure on health care in 2008 and an increase in unemployment in 2011, are located on the peripheries of Europe, i.e. Denmark, Cyprus, Greece, Spain and Portugal. The same tendency was observed in some Balkan countries - Croatia and Serbia - and also in Central and Eastern Europe. Only one country - Iceland - lowered its health care expenditure. Developments were similar as regards the number of physicians - only in Iceland did it fall per 100,000 inhabitants. As regards the number of hospital beds, only a few countries effected an increase thereof during the analysed period. However, we can observe that the more data is put on a map the harder is to interpret it. This is caused by the fact that human perception is limited.

These dependencies also need to be proven by statistical tests and authors are aware of this fact.

\section{Conclusions}

The previsualisation of the table may be a sufficient method for a specialist to indicate dependencies and explain the relations occurring between them. In the present deliberations, the previsualisation of the table has been considered solely as a stage necessary to create statistical maps, which offers considerable opportunities for cartographic visualisation, from a minimum to a maximum of information concerning the number of beds, physicians, expenditure on health care, unemployment, or political divisions. Linking table previsualisation with map visualization can support drawing conclusions from unrelated information. Combined in one visualisation, allowing us to draw conclusions on causes of the processes. For this reason the authors suggest that the previsualisation be used together with a map, and conclusions drawn on the basis of these two sources. In the article we have strived to present these two methods of graphical activity as complementary, ensuing from a pragmatic approach in cartography, which is understood to be user-friendly, i.e. ensuring intuitive legibility (Medyńska-Gulij, 2011). As regards health care data, this approach is significant, for it concerns both the public user and the health care expert.

The wage of the previsualisation method will allow specialists to disclose new dependencies following from the spatial displacement of the aforementioned indices and their time interpretation, and also present their conclusions in a new, broader spatio-temporal approach (Van Doorslaer and Van Vliet, 1989; Appleby, 2013). The value of the new conclusions may lead to a recalculation of costs connected with health care in the context of neighbourhood (Green, 2002; Green and Nguyen, 2001). The previsualisation may constitute an important stage in weighing and creating spatial health care models (Chakrabortty et al., 2014; Oliveira, Portela, and Abelha, 2014).

Data classification is already implemented in GIS software packages and allows to steer the number of classes from attribute data, the class formation principle, and the cartographic method is applied. Also styling statistical table with colours is 
also available in Office software. What is not available in commercial software, is a specific styling of the tables together with classification of data. Different method of classification is adopted from GIS software and needs user effort to classify data.

The essence of previsualisation is the appropriate arrangement of columns and rows in the table, and allocating graphic variables thereto. The proper arrangement of columns and rows in the table is subjective. The structure of the table is a question of dispute, and continues to constitute the subject of further scientific analysis. It may be that a different arrangement of columns and rows in the table will lead to different conclusions. Similarly, the allocation of graphic variables is still debatable. The problem lies in the fact that the colours selected in the study are not associated with the analysed phenomenon. The choice of different colours may impact conclusions. However, usage of the same colour palette and same data classification in the map as well as in the statistical table is necessary for drawing conclusions. For this reason that authors consider it necessary to continue research into the selection of visual variables in the process of previsualisation and the technological utilisation of mapping techniques and the effectiveness of the perception of the methods proposed herein by public users and experts.

\section{Aknowledgments}

The paper is the result of research on visualization methods carried out within statutory research in the Department of Cartography and Geomatics, Adam Mickiewicz University in Poznan, in Poland.

\section{References}

Appleby, J. (2013). The hospital bed: On its way out? British Medical Journal, 346(7899), Article number f1563. DOI: http://dx.doi.org/10.1136/bmj.f1563.

Artazcoz, L., Benach, J., Borrell, C. and Cortès, I. (2004). Unemployment and Mental Health: Understanding the Interactions Among Gender, Family Roles, and Social Class. American Journal of Public Health, 94(1), 82-88. DOI: 10.2105/AJPH.94.1.82.

Bhowmick, T., Robinson, A.C., Gruver, A., MacEachren, A.M. and Lengerich, E.J. (2008). Distributed usability evolution of the Pennsylvania Cancer Atlas. International Journal of Health Geographics, 7, 36. DOI: 10.1186/1476-072X-7-36.

Chakrabortty, R.K., Asadujjaman, M. and Nuruzzaman, M. (2014). Fuzzy and AHP approaches for designing a hospital bed: A case study in Bangladesh. International Journal of Industrial Systems Engineering, 17(3), 315-328. DOI: 10.1504/IJISE.2014.062541.

Cybulski, P. (2014). Presentation of spatio-temporal data in the context of information capacity and visual suggestiveness. Geodesy and Cartography, 63(2), 147-159. DOI: 10.2478/geocart-2014-0011.

Delamater, P.L., Messina, J.P., Grady, S.C., WinklerPrins, V. and Shortridge A.M. (2013). Do More Hospital Beds Lead to Higher Hospitalization Rates? A Spatial Examination of Roemer's Law(spatial analysis). PLoS One, 8(2), Article number e54900. DOI: 10.1371/journal.pone.0054900.

Dent, B.D. (2008). Cartography: thematic map design. Boston: WBC/McGraw-Hill.

Ferguson, J. (2002). The role of privy council nominees. Pharmaceutical Journal, 269(7209), 157. 
Gaynor, M. and Anderson, G.F. (1995). Uncertain demand, the structure of hospital costs, and the cost of empty hospital beds. Journal of Health Economics, 14, 291-317. DOI: 10.3386/w4460.

Green, L.V. (2002). How Many Hospital Beds? Inquiry : a journal of medical care organization, provision and financing, 39(4), 400-412. DOI: DOI: 10.5034/inquiryjrnl_39.4.400.

Green, L.V. and Nguyen, V. (2001). Strategies for cutting hospital beds: The impact on patient service. Health Services Research, 36(2), 421-442. DOI: 10.1177/1077558715572388.

Ham, C., York, N., Sutch, S. and Shaw, R. (2003). Hospital bed utilisation in the NHS, Kaiser Permanente, and the US Medicare programme: Analysis of routine data. British Medical Journal, 327(7426), 1257-1260. DOI: http://dx.doi.org/10.1136/bmj.327.7426.1257.

Jenks, G.F. (1967). The Data Model Concept in Statistical Mapping. International Yearbook of Cartography, 7, 186-190.

Joseph, A.E. and Phillips, D.R. (1984). Accessibility and utilization: geographical perspectives on health care delivery. New York, Harper Row.

Khan, A.A. (1992) An integrated approach to measuring potential spatial access to health care services. Socio-Economic Planning Sciences, 26(4), 275-287. DOI: 10.1016/0038-0121(92)90004-O.

Kowarik, A., Meindl, B. and Templ, M. (2015). SparkTable: Generating graphical tables forwebsites and documents with R. R Journal, 7(1), 24-37.

Klemm, P., Oeltze-Jafra, S., Lawonn, K., Hegenscheid, K., Volzke, H. and Preim, B. (2014). Interactive Visual Analysis of Image-Centric Cohort Study Data. IEEE Transactions on Visualization and Computer Graphics, 20(12), 1673-1682. DOI: 10.1109/TVCG.2014.2346591.

Kraak, M-J. and Ormeling, F. (2010). Cartography. Visualization of Spatial Data. $3^{\text {rd }}$ edn. London, Prentice Hall.

Kroneman, M. and Siegers, J. (2004). The effect of hospital bed reduction on the use of beds: A comparative study of 10 European countries. Social Science and Medicine, 59, 1731-1740. DOI: 10.1016/j.socscimed.2004.01.036.

Mayer, E., Moyen, S. and Stähler, N. (2010). Government Expenditures and Unemployment: A DSGE Perspective. Bundesbank Discussion Paper, Series 1, No. 18/2010.

Medyńska-Gulij, B. (2011). Kartografia i geowizualizacja. Warszawa. Wydawnictwo Naukowe PWN.

Medyńska-Gulij, B. (2014) Cartographic sign as a core of multimedia map prepared by non-cartographers in free map services. Geodesy and Cartography, 63, 55-64. DOI: 10.2478/geocart-2014-0004.

Mosseveld, C.J.P.M. (2003). International comparison of health care expenditure, existing frameworks, innovations and data use. Netherlands: Statistic Netherlands, Voorbugr.

Ocaña-Riola, R. (2010) Common Errors in Disease Mapping. Geospatial Health, 4(2), 139-154.

Oliveira, S., Portela, F., Santos, M.F., Machado, J. and Abelha, A. (2014). Predictive models for hospital bed management using data mining techniques. Advances in Intelligent System and Computing, 276(2), 407-416. DOI: 10.1007/978-3-319-05948-8_39.

Ratajski, L. (1989). Metodyka kartografii społeczno-gospodarczej. $2^{\text {nd }}$ Edn. Warszawa, Wrocław, Państwowe Przedsiębiorstwo Wydawnictw Kartograficznych.

Schweikart, J. and Kistemann, T. (2013). Mapping Health and Health Care. Kartographische Nachrichten, $1,3-11$.

Slocum, T.A., McMaster, R.B., Kessler, F.C. and Howard, H.H. (2009). Thematic cartography and geovisualization. $3^{\text {rd }}$ edn. Englewood Cliffs, NJ: Prentice Hall.

Van Doorslaer, E.K.A. and Van Vliet, R.C.J. (1989). 'A builtbed is a filled bed?' An empirical reexamination. Social Science and Medicine, 28, 155-164. DOI: 10.1016/0277-9536(89)90143-3.

Wei, Luo. (2004). Using a GIS-based floating catchment method to assess areas with shortage of physicians. Health \& Place, 10(1), 1-11. DOI: 10.1016/S1353-8292(02)00067-9. 